\title{
Frontier models for evaluating environmental efficiency: an overview
}

\author{
Alfons Oude Lansink ${ }^{1}$ Alan Wall ${ }^{2 *}$ \\ ${ }^{1}$ Wageningen University, Business Economics Group, The Netherlands \\ ${ }^{2}$ University of Oviedo, Oviedo Efficiency Group, Spain
}

Received: 5 February 2014

Revised: 27 February 2014

Accepted: 1 March 2014

\begin{abstract}
Our aim in this paper is to provide a succinct overview of frontier-based models used to evaluate environmental efficiency, with a special emphasis on agricultural activity. We begin by providing a brief, up-to-date review of the main approaches used to measure environmental efficiency, with particular emphasis on eco-efficiency models, the materials balance approach and the exergy balance approach. We then review the principal contributions analyzing the determinants of environmental efficiency, and finish by providing some suggestions for future research.
\end{abstract}

Keywords: environmental efficiency, agriculture, frontier, eco-efficiency

JEL Classification Codes: D22, Q15, Q56, Q57

\section{Introduction}

Concerns about the environmental impact of economic activity have now become central to policymaking. In particular, the negative environmental impacts of agricultural activity are well-documented and include pollution and degradation of soil, water and air through the use of pesticides, manure and chemical fertilizers (OECD, 2008). At international level this has led to policy responses such as the European Union's (EU) 1991 Nitrates Directive and its proposed Water Framework Directive. Also, environmental concerns play a central role in the recent reform of the EU's Common Agricultural Policy (CAP), which provides for the allocation of direct aid payments for respecting certain agricultural practices beneficial for the climate and the environment and obliges Member States to spend part of their rural development funding on measures including the fight against climate change (European Commission, 2013). There seems little question that the assessment of environmental performance will become an increasingly important focus of economic research.

\footnotetext{
* Corresponding author. E-mail: awall@uniovi.es.

Citation: Oude Lansink, A and A. Wall (2014) Frontier models for evaluating environmental efficiency: an overview, Economics and Business Letters, 3(1), 43-50.
} 
It is important to measure environmental efficiency as well as to identify its determinants in order to evaluate existing environmental policies and design new policies. The desire to reduce the environmental impact of agricultural activity leads naturally to the idea of more efficient use of resources, from which it is clear that efficiency (frontier) analysis has a valuable role to play (see Fried et al., 2008, for an overview of frontier techniques). Indeed, since the end of the 1980s, a large and growing literature has developed on the application of frontier techniques - particularly Data Envelopment Analysis (DEA) and Stochastic Frontier Analysis (SFA) - to measuring environmental efficiency applied to agriculture. In this paper we provide a brief introduction to this literature and draw attention to some recent developments which provide openings for future research.

\section{Approaches to measuring environmental efficiency}

In an early survey of the measurement of environmental performance from a productive efficiency perspective, Tyteca (1996) noted that environmental indicator approaches such as Life Cycle Analysis and Environmental Impact Assessment (see Hoang and Alauddin, 2012, for further references to indicator-based approaches) have the drawback compared to frontierbased approaches that they are not suited for comparisons among producers and over time. The literature incorporating environmental concerns into conventional frontier-based efficiency and productivity analysis can be classified into several groups depending on how environmental damage ("pollution") is dealt with. Tyteca $(1996,1997)$ describes two types of frontier-based environmental efficiency models. The first type involves standard SFA or DEA efficiency models adjusted for pollution, whereas the second relates economic outcomes to ecological outcomes rather than "true" inputs. Lauwers (2009), who labeled these "environmentally adjusted production efficiency" (EAPE) and "frontier eco-efficiency" (FEE) models respectively, describes a third type of model by advocating the incorporation of the materials balance principle into frontier-based environmental efficiency models. In doing so, the environmental outcome is derived explicitly from the production process. Studies incorporating the materials balance condition have become increasing prevalent in agricultural environmental efficiency analysis. However, it has recently been argued that existing studies using the materials balance approach have some limitations, and what can be considered a fourth type of model - the exergy balance approach - has recently been proposed by Hoang and Rao (2010) in response to some of these limitations.

\subsection{Treating pollutants as an additional input or undesirable output variable}

In the pioneering frontier-based studies evaluating the relative environmental performance of producers the environmental effect ("pollution") was modeled as an additional variable, either as a bad output or an environmentally detrimental input. Färe et al. (1989) incorporated pollution as a bad output and proposed hyperbolic DEA efficiency measures to evaluate environmental performance. While desirable outputs were assumed to be strongly disposable (i.e., can be reduced at no cost), bad or undesirable outputs were treated as weakly disposable implying that their production could only be reduced by reducing desirable outputs (or increasing inputs) and is therefore costly. An alternative approach has been to consider pollution as (strongly disposable) detrimental inputs in production processes, and prominent applications in agriculture include Reinhard et al. (1999, 2000) and Hailu and Veeman (2001). Several applications of environmentally-adjusted production efficiency models have been made to agriculture using a wide range of approaches including input and output distance functions and directional distance functions (see, for example, Piot-Lepetit and Vermerch, 1998; Reinhard et al., 1999, 2000, 2002; Shaik et al. 2002; Oude Lansink and Silva, 2003; 
Piot-Lepetit and Le Moing, 2007). Asmild and Hougaard (2006), who disaggregated the nutrient surpluses into input and output flows, discuss some of the issues involved with considering pollution as an undesirable output or input. Useful surveys on these issues from a DEA perspective include Scheel (2001), Dyckhoff and Allen (2001) and Zhou et al. (2008). A similar discussion can also be found in Skevas et al. (2012), who also account for the dynamic effects of polluting inputs in frontier models.

\subsection{Frontier Eco-efficiency Models}

Rather than relating conventional inputs to outputs, eco-efficiency is traditionally conceptualized as a ratio that can be expressed as an indicator of economic value divided by an indicator of environmental impact (Schmidheiney, 1993; OECD, 1998; WBCSD, 2000). Hence, this concept of environmental performance explicitly takes into account both the economic and ecological dimensions of productive activity. Kuosmanen and Kortelainen (2005) point out that measurement of eco-efficiency is critically important as an improvement of eco-efficiency is often the most cost-effective way of reducing environmental pressures, and policies targeted at efficiency improvements are more easily implemented than policies that restrict the level of economic activity.

Production frontier models provide a natural tool in measuring the eco-efficiency of producers and Lauwers (2009) refers to these frontier eco-efficiency (FEE) models as the "frontier operationalization" of the traditional eco-efficiency concept insofar as these FEE models relate ecological and economic outcomes rather than the conventional inputs and outputs. Early studies following this approach are Callens and Tyteca (1999) and Tyteca (1999). Kuosmanen and Kortelainen (2005) proposed a definition of eco-efficiency based on what they label as the "pressure-generating technology set", which represents all feasible combinations of economic value and environmental pressures (damage), and treat environmental pressures as conventional inputs in an application to Finnish road transportation using DEA. Kortelainen (2008) presents a framework for dynamic environmental performance analysis that generalized the method of Kuosmanen and Kortelainen (2005) from a static to a dynamic setting using the Malmquist productivity index. Picazo-Tadeo et al. (2014) extend this approach to the assessment of intertemporal environmental performance and its determinants at the level of the management of specific pollutants using directional distance functions and Luenberger productivity indicators.

Given the pressure-generating technology set, environmental efficiency can easily be estimated with input distance functions using DEA or SFA. This approach has been followed in applications to agriculture by Picazo-Tadeo et al. (2011) and Picazo-Tadeo et al. (2012). Both papers provide detailed references to methodological and empirical contributions to the eco-efficiency literature. See also Beltrán-Esteve et al. (2014) for an analysis using metafrontiers to assess technological differences in eco-efficiency between groups of producers with an application to olive growers.

\subsection{The materials balance approach}

Rather than treating pollution as an additional variable, an alternative approach to modeling environmental efficiency is to incorporate the materials balance principle (MBP), which implies that nutrients not contained in good outputs go back into the environment as potential pollutants (Lauwers et al., 1999; Reinhard and Thijssen, 2000; Coelli et al., 2007). As noted by Hoang and Coelli (2011), agricultural production activities, as part of an ecosystem, are regulated by the law of mass conversation, implying that the nutrients balance condition holds true. As such they argue that measures of efficiency and productivity growth in agricultural production have to satisfy the test of the materials balance condition. 
In line with this, the measurement of environmental performance by incorporating an extra polluting variable as an input or (weakly disposable) bad output in frontier models was signaled as problematic by Coelli et al. (2007) on the grounds that these methods do not satisfy the materials balance condition. Coelli et al. (2007) demonstrated this violation using the materials balance approach for the groups of input- and output-oriented models and provided an application to Belgian pig farms, while Hoang and Coelli (2011) provided a proof for the directional distance functions and include an application to the agricultural industry in OECD countries. DEA was used in both cases. Van Meensel et al. (2010) compared DEA, stochastic frontier analysis and a mechanistic frontier approach in another application to Belgian pig farming. More recently, Hoang and Nguyen (2013) also compared stochastic frontier analysis and DEA in an application to rice farms on South Korea, and is a useful source of references to this literature.

\subsection{The exergy balance approach}

It has recently been argued that existing studies using the materials balance approach have some limitations. In particular, Hoang and Rao (2010) argue that the materials balance approach provides an ambiguous treatment of immaterial inputs (e.g., labour, capital, farm services) and suffers from a lack of universally-accepted weights for various materials. To overcome these limitations the authors advocate the incorporation into frontier analysis of environmental performance of an exergy balance, where exergy refers to the usefulness or value of any forms of mass and energy. Incorporating the cumulative exergy balance over the supply chain permits cumulative pollution and the total effects of agricultural activity on natural resources to be incorporated into models. Doing so permits a more comprehensive evaluation of the sustainability of eco-systems and the approach is therefore compatible with the Life Cycle Analysis framework. Hoang and Rao (2010) introduce the concept of Sustainable Efficiency (SE), defined as the ratio of total to minimum cumulative exergy content, which can easily be measured by standard frontier techniques. They provide an empirical application using input-oriented DEA to OECD agriculture.

While cumulative exergy contents can better capture aggregate effects of cumulative pollution and overall resource use, Hoang and Alauddin (2012) point out that the materials balance approach is still perfectly useful for evaluating specific types of pollution. Thus, if researchers are interested in analysing specific types of pollution as well as overall pollution and resource extraction, the two approaches can be combined. In an application to an agricultural dataset for OECD countries, Hoang and Alauddin (2012) incorporate both the materials balance and exergy balance into a frontier framework and show how standard frontier models can be used to evaluate cost efficiency, environmental efficiency (material balance) and ecological efficiency (exergy balance).

\section{Determinants of environmental efficiency}

While there is a vast literature on the estimation of the magnitude and variation of environmental efficiency across producers, far less attention has been given to its determinants.

Among the environmentally-adjusted production efficiency models, Reinhard et al. (2002) estimated determinants of environmental efficiency for dairy farms. Using SFA, they propose a two-stage approach which allows the modeling of environmental efficiency determinants in the second stage. Explanatory variables for efficiency included proxies for labour quality (age, education, training, proxies for motivations etc), the physical environment and the institutional environment (see also Galdeano-Gómez et al., 2006). However, a substantial 
portion of environmental efficiency remained unexplained and the authors recommend complementary methods such as interviewing farmers to ascertain more about their objectives and attitudes. These factors could be influential in determining environmental performance and obtaining insights into their role could facilitate the design of farmer-oriented strategies and policies towards reducing environmental pollution.

Skevas et al. (2012) analyse the dynamic effects of pesticides in a study of Dutch arable farms and use producer-specific and environmental variables to explain inefficiency in a bootstrap truncated regression model based on Simar and Wilson (2007). Environmental efficiency was negatively related to farm size, the age of farmers, and crop subsidies, and positively related to crop rotation. They also introduced variability in weather conditions (temperature and precipitation levels) to capture the effect of production uncertainty on environmental efficiency and found it had a significant effect.

Within the frontier eco-efficiency models, Picazo-Tadeo et al. (2011) estimate ecoefficiency scores for a sample of Spanish farms and then use truncated regression and bootstrapping techniques to analyse the determinants of eco-efficiency following the procedures in Simar and Wilson (2007). The authors provide several references to the previous literature on the determinants of farmer eco-efficiency and based on this review include a series of socio-economic variables related to farmer features (age, education, income derived from farming) and farm features (size, qualification for agri-environmental benefits). Education and agri-environmental programs were found to influence eco-efficiency, and the authors advocate the inclusion in future studies of farmer features such as their level of concern for the environment. This conclusion is supported by Pérez-Urdiales et al. (2013), who found farmers' attitudes to influence eco-efficiency for a sample of Spanish dairy farms.

Finally, environmental efficiency analyses incorporating the materials balance principle (MBP) are relatively recent, with the consequence that studies involving its determinants in this framework are understandably scarce. An important exception is Hoang and Nguyen (2013), which uses an MBP approach to analyse the determinants of environmental inefficiency for a sample of rice farms in South Korea using SFA (Battese and Coelli, 1995) as well as a non-parametric two-stage procedure proposed by Simar and Wilson (2007). The explanatory variables included land size, share of rented land, intensity of fertilizer use and cost allocative efficiency, all of which were found to reduce environmental efficiency, and a series of dummies representing age groups and geographical regions which yielded contrasting results. The significance of the determinants varied substantially across models, and the authors advocate reporting results from different models. They also recognize that several socio-economic factors such as education, gender and receipt of subsidies which were unavailable in their data-set should be included.

\section{Conclusions and some suggestions for future research}

Researchers carrying out assessments of environmental efficiency in agriculture can choose between (i) models which relate conventional inputs to outputs and (ii) eco-efficiency models which relate economic outcomes to environmental pressures. Given the physical characteristics of agricultural activity, in the first case the materials balance principle should be incorporated to correctly reflect the production process. Eco-efficiency models, on the other hand, use environmental pressures rather than conventional inputs, so that the materials balance principle is not an issue. The incorporation of the exergy balance to frontier models provides researchers with the ability to assess ecological efficiency, and the exergy balance approach is consistent with Life Cycle Analysis (LCA). Indeed, analyses combining LCA with DEA have recently appeared in the literature (see Mohammadi et al., 2013, for references). 
Some recently proposed extensions to existing materials balance models have opened up promising areas of research. In particular, Kuosmanen and Kuosmanen (2013) note that materials balance accounting in these studies is static and therefore ignores the delayed environmental effects of nutrient use in agriculture that occur over a relatively long time horizon. They propose a dynamic material balance model grounded in the standard capital accumulation model and argue that the incorporation of the dynamic material balance equation could provide more meaningful productive efficiency analyses of environmental performance or eco-efficiency.

Moreover, production uncertainty, which is an inherent characteristic of agricultural production, has barely featured in environmental efficiency analyses. An exception is Skevas et al. (2012) who used variability in production conditions to explain farmers' environmental performance. More recently, Serra et al. (2014) measured environmental performance for a sample of Catalan crop farms in a state contingent production framework (Chambers and Quiggin, 2000). Guesmi (2013) analysed environmental efficiency of Spanish crop farms by incorporating the material balance approach of Coelli et al. (2007) into the state-contingent framework, which again is a promising line of future research.

Future research into environmental efficiency, irrespective of the methodological approach, would also benefit greatly from more accurate on-farm measurement of environmental pressures such as emissions of pollutants to the air, soil and water and their impact on biodiversity. Combining such data with farm accountancy data and data on weather and soil conditions would allow for a much richer analysis. Also, the results of such an analysis would provide much more detailed insights to policy makers.

Finally, much more research is needed into the determinants of environmental efficiency. Analyses based on the use of micro data sets containing information on farmers' attitudes towards risks and environmental issues and objectives have been particularly lacking in the literature, and would provide particularly useful information to policymakers.

Acknowledgements. The authors are grateful to the Guest Editor and an anonymous referee for helpful comments.

\section{References}

Asmild, M. and Hougaard, J.L. (2006) Economic versus environmental improvement potentials of Danish pig farms, Agricultural Economics, 35, 171-181.

Battese, G.E. and Coelli, T.J. (1995) A model for technical inefficiency effects in a stochastic frontier production function for panel data, Empirical Economics, 20, 325-332.

Beltrán-Esteve, M., Gómez-Limón, J-A., Picazo-Tadeo, A.J. and Reig-Martínez, E. (2014) A metafrontier directional distance function approach to assessing eco-efficiency, Journal of Productivity Analysis, 41, 69-83.

Callens, I. and Tyteca, D. (1999) Towards indicators of sustainable development for firms: A productive efficiency perspective, Ecological Economics, 28, 41-53.

Chambers, R.G. and Quiggin, J. (2000) Uncertainty, production, choice, and agency, Cambridge: Cambridge University Press.

Coelli, T., Lauwers, L. and Huylenbroeck, G.V. (2007) Environmental efficiency measurement and the materials balance condition, Journal of Productivity Analysis, 28, 3-12.

Dyckhoff, H. and Allen, K. (2001) Measuring ecological efficiency with data envelopment analysis (DEA), European Journal of Operational Research, 132, 312-325. 
European Commission (2013) CAP Reform - an explanation of the main elements. European Commission, Brussels. http://ec.europa.eu/agriculture/cap-post-2013/index_en.htm.

Färe, R., Grosskopf, S., Lovell, C.A.K. and Pasurka, C. (1989) Multilateral productivity comparisons when some outputs are undesirable: a nonparametric approach, Review of Economics and Statistics, 71, 90-98.

Fried, H., Lovell, C.A.K. and Schmidt, S. (2008) The measurement of productive efficiency and productivity growth, Oxford University Press, Oxford.

Galdeano-Gómez, E., Céspedes-Lorente, J. and Rodríguez-Rodríguez, M. (2006) Productivity and environmental performance in marketing cooperatives: an analysis of the Spanish horticultural sector, Journal of Agricultural Economics, 57(3), 479-500.

Guesmi, B. and Serra, T. (2013) Technical and environmental efficiency of Catalan arable crop farms, paper presented at XIII European Workshop on Efficiency and Productivity Analysis, Helsinki.

Hailu, A. and Veeman, T.S. (2001) Non-parametric productivity analysis with undesirable outputs: An application to the Canadian pulp and paper industry, American Journal of Agricultural Economics, 83, 605-616.

Hoang, V.-N. and Alauddin, M. (2012) Input-orientated Data Envelopment Analysis framework for measuring and decomposing economic, environmental and ecological efficiency: an application to OECD agriculture, Environmental and Resource Economics, 51, 431-452.

Hoang, V.-N. and Coelli, T. (2011) Measurement of agricultural total factor productivity growth incorporating environmental factors: a nutrients balance approach, Journal of Environmental Economics and Management, 62(3), 462-474

Hoang, V.-N. and Rao, D.S.P. (2010) Measuring and decomposing sustainable efficiency in agricultural production: a cumulative exergy balance approach, Ecological Economics, 69(9), 1765-1776.

Hoang, V.-N. and Nguyen, T.T. (2013) Analysis of environmental efficiency variations: a nutrient balance approach, Ecological Economics, 86, 37-46.

Kortelainen, M. (2008) Dynamic environmental performance analysis: a Malmquist index approach, Ecological Economics, 64(4), 701-715

Kuosmanen, T. and Kortelainen, M. (2005) Measuring eco-efficiency of production with data envelopment analysis, Journal of Industrial Ecology, 9(4), 59-72.

Kuosmanen, N. and Kuosmanen, T. (2013) Modeling cumulative effects of nutrient surpluses in agriculture: a dynamic approach to material balance accounting, Ecological Economics, 90, 159-167.

Lauwers, L. (2009) Justifying the incorporation of the materials balance principle into frontier-based eco-efficiency models, Ecological Economics, 68, 1605-1614.

Mohammadi, A., Rafiee, S., Jafari, A., Dalgaard, T., Trydeman Knudsen, M., Keyhani, A., Mousavi-Avval, S.H., Hermansen, J.E. (2013) Potential greenhouse gas emission reductions in soybean farming: a combined use of Life Cycle Assessment and Data Envelopment Analysis, Journal of Cleaner Production, 54, 89-100.

OECD (1998) Eco-Efficiency, OECD, Paris.

OECD (2008) Environmental performance of agriculture in OECD countries since 1990, Paris. http://www.oecd.org/greengrowth/sustainable-agriculture/44254899.pdf

Oude Lansink, A. and Silva, E. (2003) CO2 and energy efficiency of different heating technologies in the Dutch glasshouse industry, Environmental and Resource Economics 24, 395-407.

Pérez-Urdiales, M., Oude Lansink, A. and Wall, A. (2013) Eco-efficiency among dairy farmers: the importance of socioeconomic characteristics and farmer attitudes, paper 
presented at XIII European Workshop on Efficiency and Productivity Analysis, Helsinki.

Picazo-Tadeo, A., Beltran-Esteve, M. and Gomez-Limon, J. (2012) Assessing eco-efficiency with directional distance functions, European Journal of Operational Research, 220, 798-809.

Picazo-Tadeo, A., Castillo, J. and Beltrán-Esteve, M. (2014) An intertemporal approach to measuring environmental performance with directional distance functions: greenhouse gas emissions in the European Union, Ecological Economics, forthcoming.

Picazo-Tadeo, A., Reig-Martínez, E. and Gómez-Limón, J. (2011) Assessing farming ecoefficiency: a data envelopment analysis approach, Journal of Environmental Management, 92(4), 1154-1164.

Piot-Lepetit, I. and Le Moing, M. (2007) Productivity and environmental regulation: the effect of the nitrates directive in the French pig sector, Environmental and Resource Economics, 38, 433-46.

Reinhard, S. and Thijssen, G. (2000) Nitrogen efficiency of Dutch dairy farms: a shadow cost system approach, European Review of Agricultural Economics, 27(2), 167-186.

Reinhard, S., Lovell, C.A.K. and Thijssen, G.J. (1999) Econometric estimation of technical and environmental efficiency: an application to Dutch dairy farms, American Journal of Agricultural Economics, 81, 44-60.

Reinhard, S., Lovell, C.A.K. and Thijssen, G.J. (2000) Environmental efficiency with multiple environmentally detrimental variables: estimated with SFA and DEA, European Journal of Operational Research, 121, 287-303.

Reinhard, S., Lovell, C.A.K. and Thijssen, G.J. (2002) Analysis of environmental efficiency variation, American Journal of Agricultural Economics, 84, 1054-1065.

Scheel, H. (2001) Undesirable outputs in efficiency valuations, European Journal of Operational Research, 132, 400-410.

Schmidheiney, S. (1993) Changing course: a global business perspective on development and the environment, Technical report, MIT Press, Cambridge, MA.

Serra, T., Chambers, R. and Oude Lansink, A. (2014) Measuring technical and environmental efficiency in a state-contingent technology, European Journal of Operational Research, forthcoming.

Shaik, S., Helmers, G.A. and Langemeier, M.R. (2002) Direct and indirect shadow price and cost estimates of nitrogen pollution abatement, Journal of Agricultural and Resource Economics, 27, 420-432.

Skevas, T., Oude Lansink, A. and Stefanou, S.E. (2012) Measuring technical efficiency in the presence of pesticide spillovers and production uncertainty: the case of Dutch arable farms, European Journal of Operational Research, 223, 550-559.

Simar, L. and Wilson, P. (2007) Estimation and inference in two-stage, semiparametric models of production processes, Journal of Econometrics, 136, 31-64.

Tyteca, D. (1996) On the measurement of the environmental performance of firms - a literature review and a productive efficiency perspective, Journal of Environmental Management, 46, 281-308.

Tyteca, D. (1997) Linear programming models for the measurement of environmental performance of firms-concepts and empirical results, Journal of Productivity Analysis, 8, 183-197.

Zhou P., Ang, B.W. and Poh, K.L. (2008) A survey of data envelopment analysis in energy and environmental studies, European Journal of Operational Research, 189, 1-18. 